\title{
PENGARUH KUALITAS PELAYANAN DENGAN KEPUASAN PASIEN DI RAWAT JALAN PENYAKIT DALAM RSUD DR. DJOELHAM BINJAI
}

\author{
The Influence Of Quality Service With The Satisfaction Of Patients In The Infection Of \\ The Disease RSUD Dr. Djoelham Binjai
}

\author{
Silvia Agustina Hasibuan ${ }^{1}$, Zulfendri ${ }^{2}$, Destanul Aulia ${ }^{3}$ \\ 1,2,3 Fakultas Kesehatan Masyarakat Universitas Sumatera Utara
}

\begin{abstract}
Abstrak
Kualitas pelayanan merupakan tingkat kesempurnaan pelayanan kesehatan yang memuaskan pelanggan yang diberikan sesuai dengan standard dan etika profesi. Kepuasan pelanggan merupakan salah satu aspek yang dipengaruhi oleh kualitas pelayanan. Salah satu sarana kesehatan yang dinilai turut adil dalam pelayanan kesehatan adalah Rumah Sakit. Penelitian ini bertujuan untuk menganalisis pengaruh kualitas pelayanan terhadap kepuasaan pasien di rawat jalan penyakit dalam RSUD Dr. RM Djoelham Binjai. Populasi dalam penelitian ini adalah seluruh pasien yang berobat ke rawat jalan penyakit dalam RSUD Dr. RM Djoelham Binjai dengan sampel sebanyak 57 pasien, yang diambil secara accidential, dengan kriteria merupakan pasien yang berobat ke rawat jalan penyakit dalam RSUD. Dr. RM. Djoelham Binjai. Hasil penelitian menunjukkan bahwa secara statistik kualitas pelayanan meliputi kehandalan $(0,008)$, jaminan $(0,030)$, bukti fisik $(0,001)$, perhatian $(0,026)$, dan daya tanggap $(0.001)$, berpengaruh signifikan terhadap kepuasan pasien rawat jalan di rawat jalan penyakit dalam RSUD Dr. RM Djoelham Binjai. Kualitas pelayanan RSUD Dr. RM Djoelham Binjai pada dasarnya telah terakreditasi paripurna. Namun untuk selanjutnya agar kualitas semakin baik lagi pihak manajemen rumah sakit harus meningkatkan standard pelayanan ke tahap internasional yang diikuti dengan langkah-lankah monitoring dan evaluasi setiap tahunnya.
\end{abstract}

Kata Kunci: Kualitas Pelayanan, Kepuasan Pasien

\begin{abstract}
Service quality is a level of perfection of health services that satisfy customers who are given in accordance with professional standards and ethics. Customer satisfaction is one aspect that is influenced by the quality of service. One health facility that is considered to be fair in health services is a hospital. This study aims to analyze the effect of service quality on patient satisfaction in outpatient internal medicine at Dr. RM Djoelham Binjai. The population in this study were all patients who sought outpatient internal medicine at Dr. RSUD. RM Djoelham Binjai with a sample of 57 patients, who were taken accidentially, with criteria being patients who went to outpatient internal medicine hospitals. Dr. RM. Djoelham Binjai. The results showed that statistically the service quality included reliability $(0,018)$, guarantee $(0,031)$, physical evidence $(0,007)$, attention $(0,022)$, and responsiveness $(0,039)$, significantly influencing the satisfaction of inpatients in outpatient internal medicine hospitals. Dr. RM Djoelham Binjai. Service quality of Dr. RM Djoelham Binjai has basically been fully accredited. But for the future so that the quality is getting better the hospital management must improve the service standard to the international stage followed by monitoring and evaluation steps every year.
\end{abstract}

Keywords: Service Quality, Patient Satisfaction

Korespondensi : Silvia Agustina Hasibuan

Email : silvyhasibuan@yahoo.co.id 


\section{PENDAHULUAN}

Kualitas pelayanan merupakan tingkat kesempurnaan pelayanan kesehatan yang memuaskan pelanggan yang diberikan sesuai dengan standard dan etika profesi. Kepuasan pelanggan merupakan salah satu aspek yang dipengaruhi oleh kualitas pelayanan. Salah satu sarana kesehatan yang dinilai turut adil dalam pelayanan kesehatan adalah Rumah Sakit. Pelayanan kesehatan di Rumah Sakit diharapkan berorientasi kepada kepuasan pelanggan, terstandar dan dapat dilakukan secara paripurna, karena pasien merupakan sumber pendapatan dari rumah sakit baik secara langsung (out of pocket) maupun secara tidak langsung melalui asuransi kesehatan. Tanpa adanya pasien rumah sakit tidak dapat bertahan dan berkembang mengingat besarnya biaya untuk operasional rumah sakit yang sangat tinggi (1). Salah satu cara utama mendiferensiasikan pelayanan jasa kesehatan termasuk pelayanan rawat jalan adalah memberikan jasa pelayanan kesehatan yang berkualitas, lebih tinggi dari pesaing secara konsisten. Kuncinya adalah memenuhi atau melebihi harapan pasien tentang mutu pelayanan yang diterimanya. Setelah menerima jasa pelayanan kesehatan pasien akan membandingkan jasa yang dialaminya dengan jasa yang diharapkan. Jika jasa yang dialami berada dibawah jasa yang diharapkan, pasien tidak berminat lagi pada penyedia pelayanan kesehatan. Jika jasa yang dialami memenuhi atau melebihi harapan, mereka akan menggunakan penyedia pelayanan kesehatan itu lagi. Fenomena mutu layanan rumah sakit secara umum merupakan isue penting dalam pelayanan kesehatan di Rumah Sakit seluruh Indonesia. Hal ini menjadi salah satu barometer akreditasi rumah sakit.
Mutu pelayanan yang dimaksud mencakup mutu layanan secara klinis maupun mutu pelayanan non klinis seperti pelayanan administrasi, pelayanan sarana dan prasarana lain yang dibutuhkan oleh pasien. Pelayanan kesehatan di Rumah Sakit yang bermutu, dan berbasis kepuasan pasien juga menjadi salah satu faktor penting dalam pelaksanaan Sistem Kesehatan yang terintegrasi dengan program Badan Penyelenggara Jaminan Sosial (BPJS) tahun 2014. Penelitian Indri, dkk (2013) di RS Elim Rantepao Makasar menemukan bahwa ada pengaruh dimensi prefesionalisme, kehandalan, aksesibilitas, dan sikap petugas terhadap kualitas layanan rumah sakit, dan kepuasan pasien (12). Menurut Imbalo S dan Pohan (2003) agar mutu berhasil dicapai, layanan kesehatan itu harus dilaksanakan dalam waktu dan cara yang tepat, oleh pemberi layanan yang tepat, dan menggunakan peralatan dan obat yang tepat, serta dengan biaya yang efisien. Ketepatan waktu dalam memberikan pelayanan merupakan hal yang harus diperhatikan demi meningkatkan kedisiplinan dan penilaian mutu yang baik dari pasien pengguna layanan. Selanjutnya Rifai (2005) menyimpulkan dalam penelitiannya bahwa persepsi masyarakat tentang kualitas jasa pelayanan kesehatan dan pengaruhnya terhadap pemanfaatan jasa pelayanan kesehatan merupakan indikator utama keberhasilan jasa pelayanan kesehatan. Berdasarkan data kunjungan pasien RSUD Dr. R.M Djoelham Binjai sepanjang tahun 2014-2017 menunjukkan hasil fluktuatif. Pada tahun 2017 jumlah pasien rawat jalan jenis umum sedikit menigkat dibandingkan tahun-tahun sebelumnya yakni ada sebanyak 8.450 , begitu pula dengan pasien BPJS yang juga meningkat yakni ada sebanyak 64.336 orang. Berdasarkan hasil 
survei awal yang peneliti lakukan pada bulan Mei 2017, diketahui dari hasil wawancara dengan 25 pasien rawat jalan yang datang ke rumah sakit selama 2 (dua) hari, diketahui bahwa $68,3 \%$ pasien menilai kurang terhadap pelayanan pengambilan kartu pasien, 53,9\% menilai cukup terhadap pelayanan antrian pasien, dan masih rendahnya penilaian pasien terhadap pelayanan perawat di poliklinik yaitu $64,4 \%$ menilai perawat di poliklinik mempunyai sikap yang kurang ramah dan kurang santun, 64,9\% juga menilai kurang puas terhadap pelayanan keperawatan oleh perawat, namun pasien merasa puas dengan pelayanan penunjang pelayanan kesehatan seperti area parkir, rumah ibadah dan pelayanan makan minum (kantin). Keadaan di atas mencerminkan bahwa adanya perbedaan persepsi pasien yang mengarah pada persepsi kurang terhadap pelayanan yang diberikan di RSUD. Dr. RM. Djoelham Binjai. Fenomena di atas secara terkini mendeskripsikan bahwa ada penilaian-penilaian yang kurang terhadap pelayanan kesehatan yang diberikan oleh para dokter, perawat maupun pelayanan manajemen lainnya terhadap pasien yang datang berobat ke RSUD. Dr. RM Djoelham Binjai. Dan hal ini menjadi suatu persoalan bagi pelayanan kesehatan ditahun berikutnya jika tidak dilakukan upaya-upaya yang strategis untuk meningkatkan minat masyarakat untuk memanfaatkan pelayanan kesehatan di RSUD. Dr. RM Djoelham Kota Binjai. Berdasarkan permasalahan penelitian, maka tujuan penelitian ini adalah untuk menganalisis pengaruh kualitas pelayanan (bukti fisik, kehandalan, daya tanggap, jaminan, dan empati) terhadap kepuasan pasien di rawat jalan RSUD Dr. RM Djoelham Binjai.

\section{METODE}

Penelitian ini adalah penelitian survey dengan pendekatan kuantitatif dan cross sectional. Penelitian ini dilakukan pada saat kunjungan pasien berobat di rawat jalan penyakit dalam RSUD. Dr RM Djoelham Binjai. Populasi dan sampel dalam penelitian ini adalah seluruh pasien yang berobat ke rawat jalan penyakit dalam di RSUD. Dr. RM. djoelham Binjai. Berdasarkan perhitungan rumus tersebut di atas, maka jumlah total sampel dalam penelitian ini adalah 57 pasien. Metode pengambilan sampel penelitian dilakukan secara accidential, dengan kriteria merupakan pasien yang berobat ke Rawat Jalan Penyakit dalam RSUD. Dr. RM. Djoelham Binjai. Analisis data dalam penelitian ini untuk pengujian hipotesis adalah menggunakan uji regresi linear berganda dengan tingkat kepercayaan $95 \%$.

\section{HASIL PENELITIAN}

\section{Karakteristik Responden}

Distribusi frekuensi karakteristik responden berdasarkan data demografi menunjukkan persentase jenis kelamin responden tertinggi adalah pada perempuan sebanyak $63,2 \%$ dibandingkan dengan jenis kelamin laki-laki yaitu sebanyak $36,8 \%$.

Persentase kelompok umur responden tertinggi adalah pada rentang umur 26-50 tahun yaitu sebanyak $78,9 \%$ dan yang terendah pada rentang umur $>50$ tahun yaitu hanya sebanyak $7 \%$. Persentase tingkat pendidikan responden tertinggi adalah pada tingkat SMA yaitu sebanyak $54,4 \%$ dan yang terendah pada tingkat SD yaitu hanya sebanyak 7\%. Persentase jenis pekerjaan responden tertinggi adalah sebagai ibu rumah tangga yaitu sebanyak $26,3 \%$ dan yang terendah adalah sebagai petani yaitu hanya sebanyak $3,5 \%$. 
Tabel 1. Distribusi Kategori Berdasarkan Kehandalan, Jaminan, Bukti Fisik, Perhatian, Daya Tanggap

\begin{tabular}{|c|c|c|c|c|c|c|c|c|c|c|}
\hline & \multicolumn{2}{|c|}{ Kehandalan } & \multicolumn{2}{|c|}{ Jaminan } & \multicolumn{2}{|c|}{$\begin{array}{l}\text { Bukti } \\
\text { Fisik }\end{array}$} & \multicolumn{2}{|c|}{ Perhatian } & \multicolumn{2}{|c|}{$\begin{array}{c}\text { Daya } \\
\text { Tanggap }\end{array}$} \\
\hline & $\mathrm{F}$ & $\%$ & $\mathrm{~F}$ & $\%$ & $\mathrm{~F}$ & $\%$ & $\mathrm{~F}$ & $\%$ & $\mathrm{~F}$ & $\%$ \\
\hline Sangat Baik & 0 & 0 & 0 & 0 & 0 & 0 & 0 & 0 & 0 & 0 \\
\hline Baik & 17 & 29,8 & 40 & 70,2 & 24 & 42,1 & 4 & 7,0 & 0 & 0 \\
\hline Cukup Baik & 35 & 61,4 & 13 & 22,8 & 32 & 56,1 & 49 & 86,0 & 43 & 75,4 \\
\hline Tidak Baik & 5 & 8,8 & 4 & 7,0 & 1 & 1,8 & 4 & 7,0 & 14 & 24,6 \\
\hline Sangat Tidak Baik & 0 & 0 & 0 & 0 & 0 & 0 & 0 & 0 & 0 & 0 \\
\hline Total & 57 & 100 & 57 & 100 & 57 & 100 & 57 & 100 & 57 & 100 \\
\hline
\end{tabular}

Tabel 2. Distribusi Kategori Berdasarkan Kepuasan

\begin{tabular}{lcc}
\hline Kepuasan & Frekuensi & Persentase \\
\hline Sangat Puas & 0 & 0 \\
Puas & 7 & 12,3 \\
Cukup Puas & 45 & 78,9 \\
Tidak Puas & 5 & 8,8 \\
Sangat Tidak Puas & 0 & 0 \\
\hline Total & $\mathbf{5 7}$ & $\mathbf{1 0 0}$ \\
\hline
\end{tabular}

Tabel 3. Hasil Uji Korelasi Product Moment

\begin{tabular}{lcc}
\hline \multicolumn{1}{c}{ Variabel } & r & p value \\
\hline Kehandalan-Kepuasan & 0,725 & 0,046 \\
Jaminan-Kepuasan & 0,699 & 0,033 \\
Bukti Fisik-Kepuasan & 0,672 & 0,026 \\
Perhatian-Kepuasan & 0,646 & 0,037 \\
Daya Tanggap-Kepuasan & 0,701 & 0,049 \\
\hline
\end{tabular}

Tabel 4. Pemodelan Akhir Analisis Regresi Linear

\begin{tabular}{|c|c|c|c|c|c|c|}
\hline \multirow{2}{*}{ Model } & \multicolumn{2}{|c|}{$\begin{array}{c}\text { Unstandardized } \\
\text { Coefficients }\end{array}$} & \multirow[t]{2}{*}{$\mathbf{T}$} & \multirow{2}{*}{$\begin{array}{c}\mathbf{p} \\
\text { value }\end{array}$} & \multicolumn{2}{|c|}{$\begin{array}{c}\text { Collinearity } \\
\text { Statistics }\end{array}$} \\
\hline & B & S.E & & & Tolerance & VIF \\
\hline Kehandalan & 1,754 & 0,187 & 0,290 & 0,018 & 0,809 & 1,237 \\
\hline Jaminan & 0,535 & 0,264 & 0,565 & 0,031 & 0,823 & 1,215 \\
\hline Bukti Fisik & 1,611 & 0,306 & 0,348 & 0,007 & 0,865 & 1,156 \\
\hline Perhatian & 0,401 & 0,348 & 0,024 & 0,022 & 0,838 & 1,193 \\
\hline Daya Tanggap & 1,336 & 0,447 & 0,582 & 0,039 & 0,815 & 1,228 \\
\hline
\end{tabular}

\section{PEMBAHASAN}

Hasil analisis uji statistik dengan penelitian ini menunjukkan bahwa nilai $\mathrm{p}$ menggunakan uji regresi linear dalam $\quad(0,018<\alpha)$ dan nilai $\beta=1,754$ yang artinya 
variabel kehandalan memiliki pengaruh yang signifikan terhadap kepuasan pasien rawat jalan di RSUD Dr. RM Djoelham Binjai. Kehandalan dokter dan perawat dalam melaksankan pelayanan kesehatan menjadi salah satu point penting yang mempengaruhi kepuasan pasien, karena kehandalan dan keterampilan petugas kesehatan dalam memberikan perawatan nantinya akan meninggalkan kesan yang baik pula bagi para pasien. Pohan (2007) menyatakan bahwa pelayanan yang baik harus dilaksankan dalam waktu dan cara yang tepat oleh pemberi pelayanan. Hasil penelitian ini juga sama dengan hasil penelitian yang didapat oleh Liharis (2010) yang menyatakan bahwa kehandalan merupakan variabel yang mempengaruhi terhadap kepuasan di Puskesmas Kabupaten Ngawi (3). Hasil analisis uji statistik dengan menggunakan uji regresi linear dalam penelitian ini menunjukkan bahwa nilai $\mathrm{p}(0,031<\alpha)$ dan nilai $\beta=$ 0,535 yang artinya variabel jaminan memiliki pengaruh yang signifikan terhadap kepuasan pasien rawat jalan di RSUD Dr. RM Djoelham Binjai. Menurut Pohan (2007), pelayanan kesehatan itu harus aman baik pasien, bagi pemberi pelayanan maupun masyarakat sekitarnya. Pelayanan kesehatan yang bermutu harus aman dari risiko cedera, infeksi, efek samping yang ditimbulkan oleh pelayanan kesehatan itu sendiri, oleh karena itu ada baiknya untuk menyusun suatu prosedur yang akan menjamin keamanan semua pihak. Hasil analisis uji statistik dengan menggunakan uji regresi linear dalam penelitian ini menunjukkan bahwa nilai $\mathrm{p}$ $(0,007<\alpha)$ dan nilai $\beta=1,611$ yang artinya variabel bukti fisik memiliki pengaruh yang signifikan terhadap kepuasan pasien rawat jalan di RSUD Dr. RM Djoelham Binjai. Pohan (2007) menyatakan bila pasien merasa nyaman dengan layanan yang ada di rumah sakit maka kenyamanan akan mempengaruhi kepuasan pasien sehingga mendorong pasien untuk datang berobat kembali. Hal ini sesuai dengan penelitian yang dilakukan oleh Mariaty (2008), menyatakan bahwa variabel bukti fisik berpengaruh terhadap kepuasan pasien (4). Sama halnya juga dengan penelitian yang dilakukan oleh Rosita (2010) yang dilakukan di Rumah Sakit Herna Medan, bahwa bukti fisik merupakan hal yang sangat nyata mempengaruhi keputusan pasien dalam penilaian kepuasan pasien (7). Hasil analisis uji statistik dengan menggunakan uji regresi linear dalam penelitian ini menunjukkan bahwa nilai $\mathrm{p}(0,0226<\alpha)$ dan nilai $\beta=0,401$ yang artinya variabel perhatian memiliki pengaruh yang signifikan terhadap kepuasan pasien rawat jalan di RSUD Dr. RM Djoelham Binjai. Parasuraman (2006) menyatakan bahwa perhatian merupakan bagian dari dimensi kualitas pelayanan yang berpengaruh terhadap kepuasan pelanggan jasa (5). Hasil penelitian ini juga sesuai dengan hasil penelitian yang dilakukan oleh Deviyanti (2015) yang menyatakan bahwa ada pengaruh perhatian terhadap kepuasan pasien (2). Hasil penelitian menunjukkan bahwa mayoritas responden menyatakan kualitas daya tanggap tidak baik sebanyak $61,4 \%$. Hasil analisis uji statistik dengan menggunakan uji regresi linear dalam penelitian ini menunjukkan bahwa nilai $\mathrm{p}$ $(0,039<\alpha)$ dan nilai $\beta=1,336$ yang artinya variabel daya tanggap memiliki pengaruh yang signifikan terhadap kepuasan pasien rawat jalan di RSUD Dr. RM Djoelham Binjai. Menurut Purwanto (2007), kepuasan pasien ditentukan oleh beberapa faktor antara lain service ability yaitu meliputi kecepatan, kompetensi, serta 
penanganan keluhan yang memuaskan untuk pasien (13). Pelayanan yang diberikan oleh dokter dan perawat dengan daya tanggap yang baik akan memberikan penanganan yang cepat pula terhadap keluhan pasien sewaktu-waktu.

\section{KESIMPULAN DAN SARAN}

Terdapat pengaruh kehandalan yang signifikan terhadap kepuasan pasien rawat jalan penyakit dalam di RSUD Dr. RM Djoelham Binjai sebesar 0,018. Terdapat pengaruh jaminan yang signifikan terhadap kepuasan pasien rawat jalan penyakit dalam di RSUD Dr. RM Djoelham Binjai sebesar 0,031. Terdapat pengaruh bukti fisik yang signifikan terhadap kepuasan pasien rawat jalan penyakit dalam di RSUD Dr. RM Djoelham Binjai sebesar 0,007.Terdapat pengaruh perhatian yang signifikan terhadap kepuasan pasien rawat jalan penyakit dalam di RSUD Dr. RM Djoelham Binjai sebesar 0,022. Terdapat pengaruh daya tanggap yang signifikan terhadap kepuasan pasien rawat jalan penyakit dalam di RSUD Dr. RM Djoelham Binjai sebesar 0,039.

Pada penelitian saran yang dapat diberikan adalah diharapkan kepada para dokter agar lebih tepat waktu dalam pemeriksaan khususnya pada bagian poli. Sebaiknya para dokter lebih meningkatkan respon terhadap pasien dalam penegakan diagnosa dengan terapi secara cepat dan tepat. Terciptanya komitmen di kalangan para dokter dalam hal kepatuhan memakai jas putih. Meningkatkan kualitas SDM dengan memberikan pelatihan seperti: excelent services dan komunikasi efektif. Diharapkan kepada para perawat agar dapat memberikan informasi dan edukasi kepada pasien terkait pengobatan yang diberikan. Lebih meningkatkan kecepatan waktu dalam hal administrasi yang dimulai dari pendaftaran sampai pengambilan obat di bagian farmasi agar para pasien tidak menunggu terlalu lama. Sebaiknya menambah ruangan agar para pasien merasa lebih nyaman lagi. Arena parkir yang sudah ada harus lebih diperluas lagi untuk memenuhi kebutuhan pasien dan keluarga pasien yang membawa kendaraan pribadi. Menyediakan tempat khusus untuk pasien penyandang disabilitas.

\section{DAFTAR PUSTAKA}

1. Andersen, Ronald et al. Equity In Health : Empirical Analysis in Social Policy. London: Cambridge Mall Bailinger Publishing; 1975.

2. Deviyanti. Pengaruh Faktor Provider dan Karakteristik Konsumen Terhadap Kepuasan Peserta Jaminan Kesehatan Naional (JKN) di Ruang Rawat Inap Rumah Sakit Islam Malahayati. Skripsi FKM USU; 2015.

3. Liharris, Erida. Pengaruh Kualitas Pelayanan Terhadap Kepuasan Pasien Rawat Inap di RSU Bunda Thamrin Medan. Tesis FKM USU; 2010.

4. Mariati S. Analisis Pengaruh Kualitas Pelayanan Dalam Kaitannya Dengan Loyalitas Pasien Rawat Inap di RS Islam Malahayati Medan.Tesis, FKM USU, Medan; 2008.

5. Parasuraman, Zeithmal, VA and A. Berry.LL, A Multiple - Item Scale Measuring Consumer Perception Of Service Quality, Journal Of Retailing, Vol 64 ( January ), p 12 35;1998.

6. Pohan,Imbalo S. Jaminan Mutu Layanan Kesehatan.Jakarta : Kedokteran EGC; 2006. 
7. Rosita S. Pengaruh Mutu Pelayanan Kesehatan Terhadap Loyalitas Pasien Rumah Sakit Herna. Jurnal FKM USU; 2010.

8. RSUD RM Djoelham Kota Binjai, Profil Kesehatan RSUD RM Djoelham Kota Binjai, Kota Binjai;2012.

9. Pohan, 2003. Jaminan Mutu Pelayanan Kehatan, Bekasi : Kesaint Blasc

10. Pohan, Imbalo.2007. Jaminan Mutu Pelayanan Kesehatan. Buku Kedokteran ECG: Jakarta.

11. Rifai, 2005. Pengaruh Persepsi Masyarakat Terhadap Pemanfaatan Pelayanan Pengobatan di Puskesmas Binjai Kota Tahun 2004, (Tesis), Medan : Program Magister Administrasi Kebijakan Kesehatan Program Studi Ilmu Kesehatan. Program Pasca Sarjana Universitas Sumatera Utara

12. Indri, dkk. 2013. Studi Kualitas Pelayanan Kesehatan Bagi Pasien Rawat Inap Peserta Asuransi Kesehatan Di Rumah Sakit Elim Rantepao Tahun 2013. Fakultas Kesehatan Masyarakat, UNHAS, Makassar

13. Purwanto, Setio.2007. "Kepuasan Pasien terhadap Pelayanan Rumah Sakit" 